ПЛ-2

\title{
ЛАЗЕРЫ В АНАЛИТИЧЕСКОЙ СПЕКТРОСКОПИИ
}

\author{
Большов М.А. ${ }^{1,2}$ \\ ${ }^{1}$ Институт спектроскопии РАН, Москва, Россия \\ ${ }^{2}$ Химический факультет Московского государственного университета им. М.В. \\ Ломоносова, Москва, Россия \\ mbolshov@mail.ru
}

DOI: 10.26902/ASFE-11_03

Появление во второй половине прошлого века интенсивных коммерческих лазеров с плавно перестраиваемой длиной волны излучения - лазеров на красителях (ЛК), привело к бурному внедрению методов лазерной спектроскопии в аналитическую химию. Независимо развивались метод лазерной флуоресценции, метод лазерно-стимулированной ионизации, метод, различные варианты метода резонансной многофотонной ионизации. Спектральная яркость ЛК на много порядков превышала яркость традиционных источников резонансного излучения, что обеспечивало значительный рост чувствительности определения малых содержаний элементов по сравнению с классическими источниками. Эти преимущества были продемонстрированы при детектировании ультрамалых концентраций свободных атомов аналитов в газовой фазе. Однако, при использовании лазерных методов в анализе реальных объектов проявились существенные проблемы, определяемые матричными эффектами. Был определен также основной недостаток лазерных методов - определение только одного элемента в одном цикле измерения (одноэлементность). Одновременно с этим происходило стремительное развитие методов элементного анализа, основанных на индуктивно связанной плазме - ИСП-АЭС и ИСП-МС. Практически к середине 90-х годов эти методы вытеснили все методы элементного анализа с использованием перестраиваемых по частоте лазеров.

Вместе с тем достаточно успешно развивались методы, использующие высокую интенсивность лазерного излучения. Сфокусированное на поверхность твердого образца излучение обеспечивало испарение материала и образование плазмы с высокой температурой в объеме над поверхностью. В простейшем варианте регистрируется эмиссия атомов или ионов аналита из различных зон плазмы - лазерно-индуцированная эмиссионная спектроскопия (ЛИЭС). В более сложном варианте испаренный материал подается потоком инертного газа в плазму (ИСП) с последующей регистрацией массспектра испаренного материала. В докладе будут проанализированы достоинства и проблемы методов ЛИЭС и ЛА-ИСП-МС.

В последние десятилетия успешно развиваются методы диагностики, основанные на абсорбционной спектроскопии (AC) с диодными лазерами (ДЛ). Эти лазеры имеют исключительно малую ширину спектральной линии (до $10^{-3} \mathrm{~cm}^{-1}$ ) и могут быстро перестраиваться в достаточно широком спектральном диапазоне (3-10 $\left.\mathrm{cm}^{-1}\right)$. В докладе будут представлены результаты использования метода ДЛАС в самых разных областях: диагностике состояния больного по выдыхаемому воздуху, поиске утечек на магистральных трубопроводах, контроле производственных процессов, определении параметров горячих зон в до- и сверхзвуковых потоках газа. 